\title{
LANDING MECHANICS OF BASKETBALL AND VOLLEYBALL ATHLETES: A KINEMATIC APPROACH
}

original paper

() Wroclaw University of Health and Sport Sciences

DOI: https://doi.org/10.5114/hm.2021.104189

\section{BRUNO LUIZ SOUZA BEDO ${ }^{1}$, GUILHERME MANNA CESAR ${ }^{2}$, VITOR LUIZ ANDRADE ${ }^{1}$, FELIPE ARRUDA MOURA ${ }^{3}$, LUIZ HENRIQUE PALUCCI VIEIRA ${ }^{1}$, RODRIGO AQUINO ${ }^{4}$, MATHEUS BARROS DOMINGOS ${ }^{1}$, PAULO ROBERTO PEREIRA SANTIAGO ${ }^{1}$}

${ }^{1}$ Biomechanics and Motor Control Laboratory, School of Physical Education and Sport of Ribeirão Preto, University of São Paulo, Ribeirão Preto, Brazil

${ }^{2}$ Institute for Rehabilitation Science and Engineering, Madonna Rehabilitation Hospitals, Lincoln, United States

${ }^{3}$ Laboratory of Applied Biomechanics, Sport Sciences Department, State University of Londrina, Londrina, Brazil

${ }^{4}$ LabSport, Post-Graduate Program in Physical Education, Center of Physical Education and Sports, Federal University of Espírito Santo, Vitória/ES, Brazil

\begin{abstract} volleyball athletes presented higher values in the sagittal plane.

\section{Introduction}

The anterior cruciate ligament (ACL) rupture is one of the most devastating injuries in sports. Unfortunately, reconstructive surgeries to ACL are well known to require prolonged recovery time, negatively influencing the individuals' athletic, educational, and personal lives [1]. Sports requiring abrupt changes of directions and constant landings are often suggested to place athletes at a high risk of ACL injuries. It is estimated that $70-80 \%$ of the injuries that take place at
\end{abstract}

Purpose. Single-leg landing is frequent in basketball and volleyball, two sports with high incidence of anterior cruciate ligament injuries. The similarity in the number of landings between these sports could be the culprit of the high incidence of injuries. However, the comparison of knee joint motion during landings in both sports has yet to be investigated. This study aimed to contrast the knee kinematics of basketball and volleyball athletes during a single-leg landing task.

Methods. Overall, 10 male athletes, 5 in basketball $(181.4 \pm 6.7 \mathrm{~cm} ; 93.21 \pm 33.06 \mathrm{~kg})$ and 5 in volleyball $(178.4 \pm 6.6 \mathrm{~cm}$, $79.11 \pm 6.46 \mathrm{~kg}$ ) performed single-leg drop landings. Differences between the groups were verified with the superposition of $95 \%$ confidence intervals. Additionally, the probability approach was applied with magnitude-based inferential statistics calculated to compare individual instants (40 ms after the initial ground contact, maximum flexion, and abduction).

Results. Different knee movement patterns were detected between the groups. While volleyball athletes showed greater knee flexion, basketball players exhibited greater knee abduction. The magnitude-based inference also demonstrated that

Conclusions. Basketball athletes exhibited greater valgus in the instants before and after ground contact. In addition, volleyball athletes showed greater knee flexion during the single-leg drop landing.

Key words: knee, joint angle, single-leg landing, anterior cruciate ligament

these at-risk sports arise during non-contact conditions, such as single-leg landings [2]. The knee joint moments increase during landing tasks; more specifically, the abduction and internal rotation moments consequently increase tensional forces to ACL. However, different landing techniques can potentially decrease the internal load to the ligaments [3].

Two sports that are known for both repetitive and multidirectional landings and high prevalence of ACL injuries are basketball [4] and volleyball [5]. In volleyball, regardless of the practice environment (beach or

Correspondence address: Paulo Roberto Pereira Santiago, Biomechanics and Motor Control Laboratory, School of Physical Education and Sport of Ribeirão Preto, University of São Paulo, Av. Bandeirantes, 3900, Ribeirão Preto - SP, Brazil, 14040-907, e-mail: paulosantiago@usp.br

Received: May 13, 2020

Accepted for publication: November 3, 2020

Citation: Bedo BLS, Cesar GM, Andrade VL, Moura FA, Palucci Vieira LH, Aquino R, Domingos MB, Santiago PRP. Landing mechanics of basketball and volleyball athletes: a kinematic approach. Hum Mov. 2022;23(1):80-88; doi: https://doi.org/ 10.5114/hm.2021.104189. 
indoor), athletes present similar lower limb muscle activation [6], and single-leg landings occur at an approximate frequency between $61 \%$ (female athletes) and $70 \%$ (male athletes) during games [7], with approximately $20 \%$ of lower limb injuries befalling to the knee joint [8] during single-leg landings [9]. Very similar findings are reported for basketball. Reina Román et al. [10] observed that athletes performed an average of 57 landings during a 40-minute training session and 70 landings during competitive games, with $18 \%$ of lower limb injuries occurring at the knee joint. Since basketball and volleyball differ in the level of physical contact, the similar high frequency of landings in both sports is likely the culprit of the high incidence of injuries.

Different researchers have investigated the incidence of injuries in sports with a high number of landings during practice. Andreoli et al. [11] reported that the lower limbs were the most affected by injuries, especially the ankle, foot, and knee. Similarly, Kilic et al. [12] found that ankle, knee, and shoulder injuries were the most common ones in volleyball. Likewise, the high knee load often observed during single-leg landings in at-risk sports can increase the probability of injuries [3]. Thus, a biomechanical investigation of knee joint motion in athletes of different modalities performing sports-related landing was warranted. We selected the single-leg drop landing (SLDL) as the experimental task because of the purported high load generated to the lower limb during its execution. Although previous studies have reported peak forces experienced across the knee joint during landings that can be 3 times greater than the body mass [13], an inverse relationship is known to occur between these forces and lower limb flexion [14] during the landing. Thus, when single-leg landings are performed with the knee joint near full extension, the loading across the joint increases along with the potential increase in the risk of injury.

Although literature shows the importance of investigating knee biomechanics during athletic landing tasks for injury prevention [15, 16], establishing the mechanism of injury is a step required prior to elaborating a prevention program [17]. Few are the studies contrasting knee biomechanics of the athletic population mentioned above. One previous work [18] used a 2-dimensional approach and found significant differences in knee valgus angles of basketball and volleyball athletes during unilateral and bilateral landing tasks. A better control (i.e., less asymmetry) of knee valgus excursions during the bilateral task was reported for basketball athletes when compared with volleyball athletes. In addition, knee valgus collapse was lessened during the unilateral task for the basketball group vs. volleyball. Thus, one can assume that between-sport differences in landing techniques may promote distinct biomechanical demands around the knee joint. Nevertheless, previous research has not investigated the comparison of landing techniques in different sports, such as basketball and volleyball. Additionally, although the 2-dimensional approach can provide enough information regarding an initial screening for injurious movement patterns [16], a more robust (i.e., 3-dimensional) analysis is warranted for a comprehensive analysis of biomechanical demands around the knee joint between sports.

The purpose of this exploratory investigation was to contrast the knee joint biomechanics of basketball and volleyball athletes during the demanding task of single-leg landing. It was hypothesized that sport-related differences in landing techniques would impact on the knee kinematics variances in these modalities.

\section{Material and methods}

\section{Subjects}

Overall, 10 collegiate male athletes (convenience sampling) with a minimum experience of 2 years of collegiate-level training and competition were divided into 2 groups: basketball (BK, $n=5$ ), with average height of $184.2 \pm 9.98 \mathrm{~cm}$, weight of $96.21 \pm 30.63 \mathrm{~kg}$, and age of $20.6 \pm 1.7$ years; and volleyball (VB, $n=5$ ), with average height of $179.2 \pm 5.97 \mathrm{~cm}$, weight of 83.11 $\pm 6.20 \mathrm{~kg}$, and age of $21.6 \pm 2.9$ years. The detailed characteristics of the players are presented in Table 1. All participants exhibited no current or previous lower limb injuries in the previous 6 months and no history of knee or ankle surgeries and were participating of volleyball or basketball program training with a frequency of 4 times/week.

\section{Experimental design}

A 5-minute self-directed warm-up was allowed for each participant. In order to simulate the lower extremity biomechanical demands of landings, we evaluated the SLDLs from a 40-cm high platform. The subjects were instructed to maintain their arms on their hips and step off the box. They were not to jump up or lower their bodies down. They were asked to land as naturally as possible with their dominant foot on the landing platform. The participants' dominant limb was determined by asking them which leg they used to kick 
B. Bedo et al., Knee kinematics of single-leg landing

Table 1. Characteristics of the basketball and volleyball athletes

\begin{tabular}{|c|c|c|c|c|c|}
\hline Discipline & Athlete & Age & Weight (kg) & Height (cm) & $\begin{array}{c}\text { Practice } \\
\text { per week (hours) }\end{array}$ \\
\hline \multirow{5}{*}{ Basketball } & 1 & 20 & 70.0 & 172 & 12 \\
\hline & 2 & 19 & 119.9 & 195 & 10 \\
\hline & 3 & 23 & 144.2 & 197 & 8 \\
\hline & 4 & 22 & 86.0 & 180 & 6 \\
\hline & 5 & 20 & 64.0 & 177 & 8 \\
\hline \multirow{5}{*}{ Volleyball } & 1 & 18 & 82.0 & 176 & 6 \\
\hline & 2 & 21 & 83.5 & 179 & 6 \\
\hline & 3 & 25 & 90.5 & 187 & 10 \\
\hline & 4 & 19 & 88.0 & 184 & 10 \\
\hline & 5 & 25 & 72.0 & 170 & 10 \\
\hline
\end{tabular}

a ball. After the initial ground contact, the players were to maintain their balance for at least $2 \mathrm{~s}$ [15]. The task was described and demonstrated to the participants and they performed SLDL as many times as needed for familiarization. All athletes rested for at least 5 minutes before data acquisition. Three SLDLs were then recorded with a 1-minute interval between the trials. Owing to the particularities and variability of shoes used by the athletes between the 2 sports (e.g., low-tops, high-tops) and their potential impact on lower limb biomechanics, all participants performed the experimental task barefoot.

\section{Procedures and data analyses}

In order to obtain 3-dimensional data, a system composed of 8 infrared MCU 240 cameras (Qualisys Medical AB, Gothenburg, Sweden) sampled at $100 \mathrm{~Hz}$ was used. A total of 20 kinematics markers were placed on specific anatomical landmarks, in accordance with the published recommendations $[15,19]$; the sites involved bilateral anterior superior iliac spines, apex of iliac crests bilaterally (aligned with the greater trochanter of the femur), first sacral vertebra, prominence of the greater trochanter of the femur, lateral and medial epicondyles of the femur, head of the fibula, anterior aspect of mid-shank, lateral and medial malleoli, lateral aspect of the calcaneal tuberosity, first and fifth metatarsal heads, and hallux.

Kinematic marker trajectories were smoothed with the $4^{\text {th }}$-order Butterworth filter with a cut-off frequency of $10 \mathrm{~Hz}$. The reference systems were defined by $i, j$, and $k$, constructed by 3-dimensional coordinates of each marker. For the thigh system, markers of prominences of greater trochanter of the femur, lateral and medial epicondyles of the femur were used. For the shank system, markers of the head of the fibula, lateral and medial malleoli were applied. With reference systems defined, calculations were performed to obtain Euler angles from rotation matrices (sequence $X Y{ }^{\prime} Z^{\prime}$ ), which represent the rotation movements in the knee joint. Thus, the knee joint angles were obtained by the rotation matrices between the 2 local coordinate systems of interest: the rotation segment (shank) around the fixed segment (thigh). Therefore, the $x y z$ axis represented movements in the sagittal [flexion (-) and extension $(+)$ ], frontal [adduction $(+)$ and abduction $(-)$, and transverse [external $(+)$ and internal $(-)$ rotation] plane, respectively. In addition, a static measurement was performed for each participant's standing neutral alignment to allow the individualization of angle values. All data were processed by using specific algorithms developed in the MATLAB ${ }^{\circledR}$ software (MathWorks Inc., Natick, USA).

As a standardization procedure, the initial foot contact with the ground (touch-down, TD) was defined as a common event for all SLDLs. The time range encompassing $0.3 \mathrm{~s}$ prior to and $1 \mathrm{~s}$ after TD was selected, which resulted in the analysis of a movement with the total time of $1.3 \mathrm{~s}$. The angle values $\left(^{\circ}\right)$ during the $40 \mathrm{~ms}$ after TD, including sagittal (S40), frontal (F40), and transverse (T40) planes [9], as well as the angle values of maximum flexion (MF) and maximum abduction (MA) were identified and compared between the groups.

\section{Statistical analysis}

Statistical analyses were performed with the MATLAB software ${ }^{\circledR}$ (MathWorks Inc. Natick, USA). The data points represented by the Euler angles were compared with the medians of the time series and their respective confidence intervals. The difference between 
the groups was verified with the superposition of 95\% confidence intervals of the median, with a significance level of $p<0.05$ [20].

In addition, for the between-group comparison of S40, F40, T40, MF, and MA, the probability approach was applied, with the magnitude-based inferential statistics calculated as recommended for studies with athletic performance [21] (confidence level: 90\%; number of independent inferences: 1; maximum risk of harm: $0.5 \%$; minimum chance of benefit: $25 \%$; benefit/harm odds ratio: 66 ). Cohen's effect size $(E S)$ was used to assist with the interpretation of between-group differences. The quantitative chances of higher or lower differences were classified as follows: $\leq 1 \%$ : almost certainly not; between $>1 \%$ and $5 \%$ : very unlikely; between $>5 \%$ and $25 \%$ : unlikely; between $>25 \%$ and $75 \%$ : possible; between $>75 \%$ and $95 \%$ : likely; between $>95 \%$ and $99 \%$ : very likely; and > 99\%: almost certain. If the chances of higher or lower differences were $>5 \%$, the true difference was assumed as unclear. This statistical treatment was used because it is suggested as relevant for analysing athletic performance and it is well suited for small sample sizes [21].

\section{Ethical approval}

The research related to human use has complied with all the relevant national regulations and institutional policies, has followed the tenets of the Declaration of Helsinki, and has been approved by the Ethics Committee of Ribeirão Preto Medical School, University of São Paulo.

\section{Informed consent}

Informed consent has been obtained from all individuals included in this study.

\section{Results}

The BK and VB athletes exhibited different knee angle values during the SLDL task. The VB group showed a greater knee flexion angle than BK. These differences were found in approximately $40 \%$ of the cycle analysed (BK: ca. $36^{\circ}$, VB: ca. $42^{\circ}$ ), and in the 0.3 -s window before TD (Figure 1A). With regard to abduction/adduction angle values (Figure 1B), differences were observed between the groups in the window prior to TD. BK showed neutral values (ca. $0.7^{\circ}$ ), while VB exhibited a slight varus angle (ca. $2.7^{\circ}$ ). In addition, immediately after TD, a slight difference was found in the abduction angle; BK demonstrated greater knee abduction than VB (noted by the non-overlap of confidence intervals). With reference to internal/external rotation angles, a difference was reported in which $\mathrm{BK}$ exhibited greater internal rotation values than VB (Figure 1C).

The magnitude-based inference analysis (Table 2, Figure 2) showed greater values of MF (BK: $38.01 \pm$ $11.24^{\circ}$; $\mathrm{VB}: 48.93 \pm 9.81^{\circ}$ ) and F40 (BK: $-17.34 \pm 6.82^{\circ}$; VB: $\left.-22.68 \pm 6.67^{\circ}\right)$ for $\mathrm{VB}$ compared with BK $(E S=$ 0.97 , almost certain; $E S=0.60$, very likely; respectively). In addition, $\mathrm{BK}\left(-5.49 \pm 1.22^{\circ}\right)$ exhibited greater values of F40 ( $E S=0.93$, likely) compared with VB $(-2.89 \pm$ $\left.2.68^{\circ}\right)$. No differences were found in the other variables of interest.

\section{Discussion}

In agreement with our hypothesis, differences were found for the flexion angle exhibited between volleyball and basketball players. Volleyball athletes showed greater flexion angles than basketballers. The knee flexion is fundamental in reducing mechanical loads across the joint, enhancing absorption of impact forces [23]. Owing to the increase in knee flexion, more energy was probably absorbed and the impact forces dampened through the joint. Chappell et al. [24] described a decrease in the knee load during the landing performance with greater knee and hip flexion. Knee flexion angles during landing can also be a consequence of the differences in the patellar tendon-tibial shaft [25]. When the knee is fully extended, ACL is perpendicular to the tibial plateau line. Hence, during

Table 2. Mean \pm standard variation and magnitude-based inference [22] of the comparisons between basketball and volleyball players during single-leg drop landing

\begin{tabular}{lccc}
\hline Condition & Basketball & Volleyball & MBI \\
\hline Rotation $40 \mathrm{~ms}$ & $4.66 \pm 2.52$ & $3.93 \pm 4.12$ & Unclear \\
Abduction $40 \mathrm{~ms}$ & $4.42 \pm 1.44$ & $3.06 \pm 3.57$ & Likely ive \\
Flexion $40 \mathrm{~ms}$ & $17.34 \pm 7.82$ & $22.18 \pm 6.67$ & Very likely ive \\
Maximum abduction & $8.09 \pm 3.03$ & $9.74 \pm 7.32$ & Possibly ive \\
Maximum flexion & $39.60 \pm 11.24$ & $47.43 \pm 9.81$ & Almost certain \\
\hline
\end{tabular}

MBI - magnitude-based inference 


\section{HUMAN MOVEMENT}

B. Bedo et al., Knee kinematics of single-leg landing
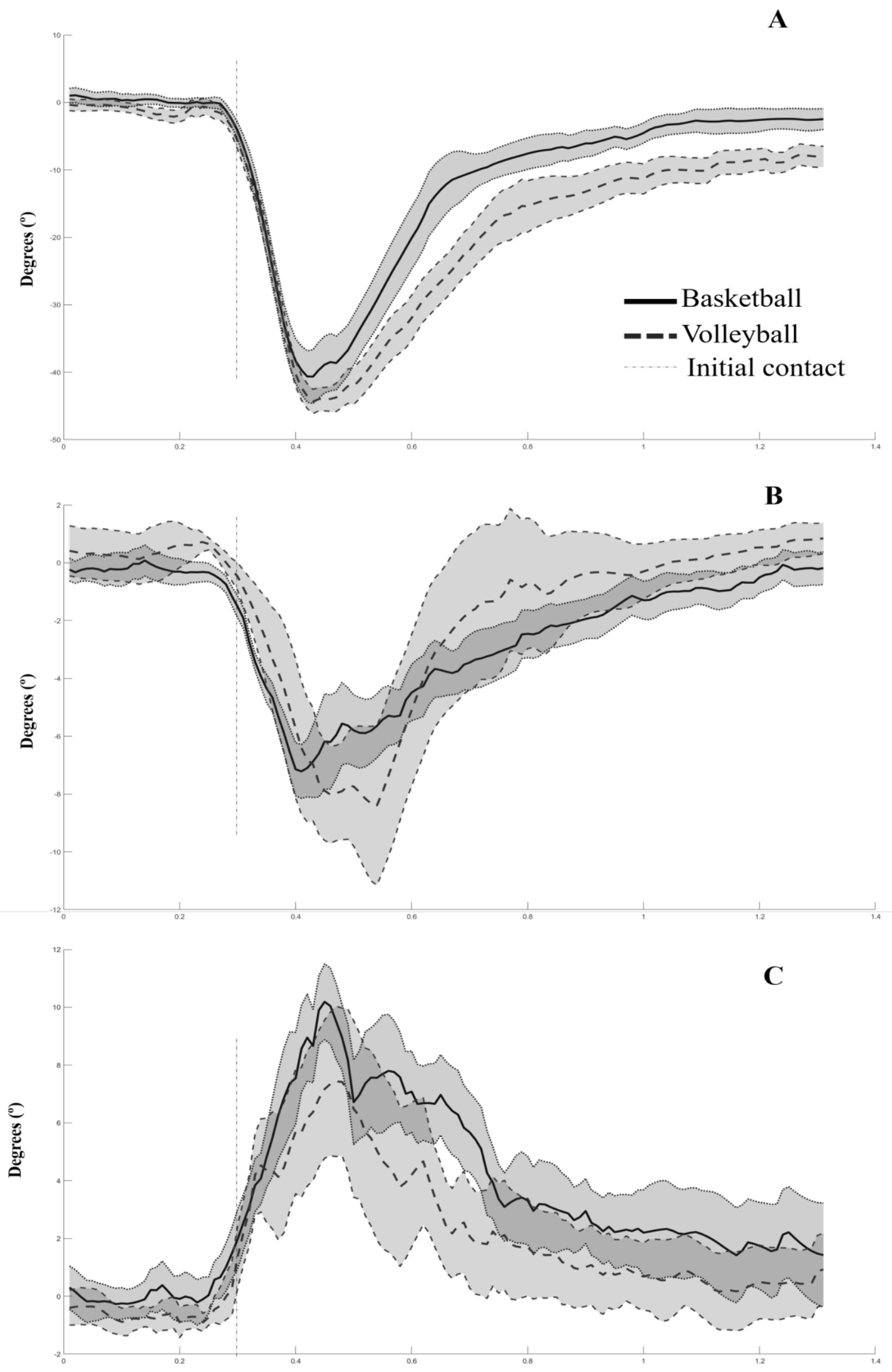

Time (s)

Figure 1. (A) Sagittal plane angles: flexion (-) / extension (+); (B) frontal plane angles: abduction (-) / adduction (+); (C) transverse plane angles: internal $(-) /$ external $(+)$ rotation 


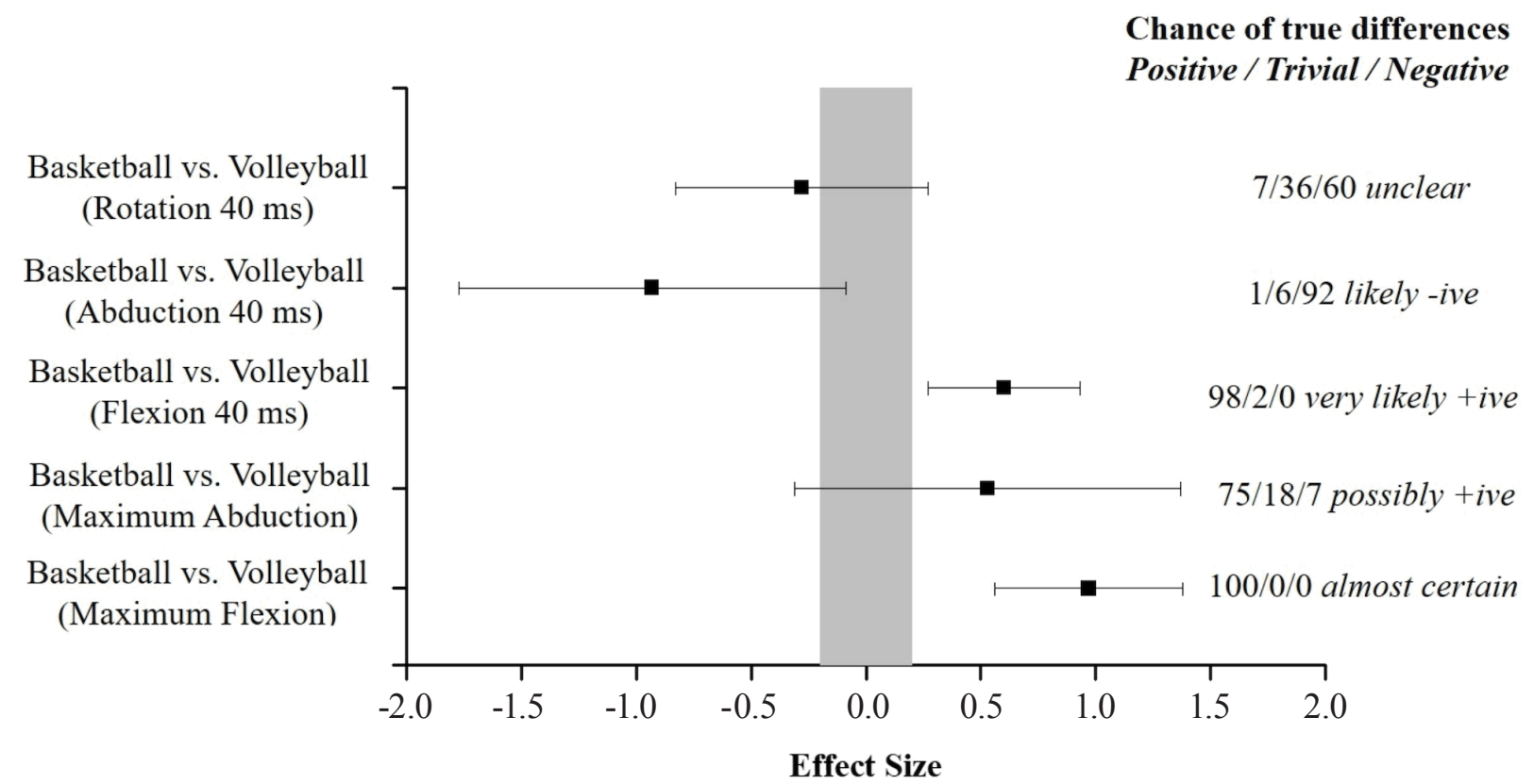

Figure 2. Magnitude-based inference of comparisons between basketball and volleyball players. FPRS = GB: $5.21 \pm 0.43$ e GV: $5.19 \pm 0.70$ (FPRS - force peak of reaction,

GB - group of basketball players, GV - group of volleyball players)

the landing performance with lower degrees of flexion, the angle between the tendon and tibial longitudinal axis decreases, thus intensifying the shear force [26]. Furthermore, the increase in the anterior tibia force increases the ACL load and, consequently, the risk of rupture. In addition, a low knee flexion angle also affects the ACL elevation angle (i.e., angle of hamstrings insertion), limiting the muscle potential to counteract anterior tibial strain [27]. The landing mechanics adopted by VB in our study can thus provide a more protective pattern (i.e., reduced loading) to the knee joint compared with the landing pattern exhibited by BK. This difference could likely explain the disparities between the groups in the frontal plane, in which BK demonstrated a trend of larger knee valgus, especially in the first instants after TD. However, at the $40 \mathrm{~ms}$ after TD, a slight (likely) difference was found, where BK exhibited greater knee abduction values.

Valgus angles and frontal plane moments are also associated with ACL ruptures [28], especially in the first milliseconds after TD. The higher knee abduction values were found in $30 \%$ and $40 \%$ of the cycle in basketball and volleyball, respectively. When considering the time after TD, these values represent 90 and $200 \mathrm{~ms}$. Although non-significant differences were observed in the frontal plane during the full-wave angle graph, when analysing the crucial instants of $40 \mathrm{~ms}$ after TD where knee injuries usually occur, a greater flexion angle was also revealed for $\mathrm{BK}$, while a greater abduction angle was detected for VB. These findings are in line with a prior study examining the time after TD when most non-contact injuries occur in handball and basketball [9]. Similar results were found by Krosshaug et al. [29]: the ligament rupture was $37 \mathrm{~ms}$ (range of 25-50 ms and 33-45 ms for males and females, respectively) during single-leg landing for basketball athletes.

The findings of no significance in the transverse plane can likely be explained by the experimental task utilized in our study. Rotational forces are known to contribute to the knee joint loading during tasks that require changes in direction and rotations in the transverse plane, such as side-step cutting manoeuvres [30]. Nonetheless, in the 0.6-s epoch, a greater internal rotation was found for VB. This difference may increase the joint load and, consequently, the risk of injuries [31].

Different techniques of single-leg landing that may increase the knee joint load were observed in this study. These differences can be a result of the differences in the neuromuscular control patterns induced by the specificity of each modality [32]. Also, the strategy adopted by basketball athletes seemed to corroborate the explanation mentioned above and could likely have resulted from foot placement during the landing. While in VB, a protective technique was used (i.e., greater flexion), BK athletes' motor actions favoured a dynamic knee abduction. In addition, the dynamics of each sport may explain the differences obtained. During practice, volleyball players perform jumps and landings during every single attack or de- 
fence situation, whereas basketballers would perform movements that require less knee flexion, such as jump shots. Therefore, the frequency and the trainability may explain the differences in the knee flexion and abduction in these modalities. Furthermore, although this study did not investigate the ankle joint, different foot placement during the landing task could have affected the knee loading [33].

Cortes et al. [33] found a higher maximum knee flexion angle when the landing was performed with forefoot in comparison with the rearfoot. Therefore, greater knee and hip flexion was observed with the forefoot technique in the time of peak vertical ground reaction force. Future research should investigate whether basketball athletes perform our experimental task with lower plantar-flexion, using a stiff landing technique that increases the vertical force reaction and, consequently, joint loading [34].

It is important to consider the limitations of the study. It had a small sample size, but a recent literature review of biomechanical studies with team sports showed a consistent low number of participants (e.g., 4 [35] and 18 [36]) in the investigations selected. We purposefully involved a small sample size for this exploratory work and used the appropriate statistical treatment (i.e., magnitude-based inference) [37] to generate the $E S$ needed to serve as the basis for further largerscale studies investigating the differences in landing techniques between sports. However, future studies should perform similar analyses but using a bigger sample size. Another potential limitation is that this investigation was conducted in a controlled laboratory environment with a fixed target and no interference from opponents; we suggest that further investigations should be performed on the court in order to obtain a more ecologically-related approach. Furthermore, we only recruited male athletes; future work should also compare the landing mechanics of female athletes of different modalities. Lastly, we understand that the sampling rate is a limitation. Therefore, future research should use a higher sampling rate in kinematics approaches than the one applied in the current study.

\section{Conclusions}

The movement pattern of the knee joint was different between basketball and volleyball athletes when performing a single-leg landing task. Basketball players exhibited greater valgus in the first instants before and after ground contact. In addition, volleyball athletes showed greater knee flexion during SLDL.

\section{Acknowledgments}

This work was supported by the Coordenação de Aperfeiçoamento de Pessoal de Nível Superior (CAPES), Brazil (finance code: 001) and by grant \#2010/20538-7 and \#2011/14811-5, São Paulo Research Foundation (FAPESP).

\section{Disclosure statement}

No author has any financial interest or received any financial benefit from this research.

\section{Conflict of interest}

The authors state no conflict of interest.

\section{References}

1. Hewett TE, Ford KR, Myer GD. Anterior cruciate ligament injuries in female athletes: Part 2. A meta-analysis of neuromuscular interventions aimed at injury prevention. Am J Sports Med. 2006;34(3):490-498; doi: 10.1177/0363546505282619.

2. Griffin LY, Agel J, Albohm MJ, Arendt EA, Dick RW, Garrett WE, et al. Noncontact anterior cruciate ligament injuries: risk factors and prevention strategies. J Am Acad Orthop Surg. 2000;8(3):141-150; doi: 10.5435/00124635-200005000-00001.

3. Laughlin WA, Weinhandl JT, Kernozek TW, Cobb SC, Keenan KG, O’Connor KM. The effects of single-leg landing technique on ACL loading. J Biomech. 2011; 44(10):1845-1851; doi: 10.1016/j.jbiomech.2011.04.010.

4. Arendt E, Dick R. Knee injury patterns among men and women in collegiate basketball and soccer. NCAA data and review of literature. Am J Sports Med. 1995; 23(6):694-701; doi: 10.1177/036354659502300611.

5. Agel J, Rockwood T, Klossner D. Collegiate ACL injury rates across 15 sports: National Collegiate Athletic Association Injury Surveillance System data update (2004-2005 through 2012-2013). Clin J Sport Med. 2016;26(6):518-523; doi:10.1097/JSM.00000000000 00290.

6. Dal Bello F, Aedo-Muñoz E, Gomes Moreira D, Brito CJ, Miarka B, Navarro Cabello E. Beach and indoor volleyball athletes present similar lower limb muscle activation during a countermovement jump. Hum Mov. 2020;21(2):42-50; doi: 10.5114/hm.2020.89913.

7. Zahradnik D, Jandacka D, Holcapek M, Farana R, Uchytil J, Hamill J. Blocking landing techniques in volleyball and the possible association with anterior cruciate ligament injury. J Sports Sci. 2018;36(8):955961; doi: 10.1080/02640414.2017.1346817.

8. Cuñado-González Á, Martín-Pintado-Zugasti A, Rodríguez-Fernández ÁL. Prevalence and factors associated with injuries in elite Spanish volleyball. J Sport Rehabil. 2019;28(8):796-802; doi: 10.1123/jsr.2018-0044.

9. Koga H, Nakamae A, Shima Y, Iwasa J, Myklebust G, Engebretsen L, et al. Mechanisms for noncontact an- 
terior cruciate ligament injuries: knee joint kinematics in 10 injury situations from female team handball and basketball. Am J Sports Med. 2010;38(11):22182225; doi: 10.1177/0363546510373570.

10. Reina Román M, García-Rubio J, Feu S, Ibáñez SJ. Training and competition load monitoring and analysis of women's amateur basketball by playing position: approach study. Front Psychol. 2019;9:2689; doi: 10.3389/fpsyg.2018.02689.

11. Andreoli CV, Camargo Chiaramonti B, Buriel E, de Castro Pochini A, Ejnisman B, Cohen M. Epidemiology of sports injuries in basketball: integrative systematic review.BMJOpen SportExerc Med. 2018;4(1):e000468; doi: 10.1136/bmjsem-2018-000468.

12. Kilic O, Maas M, Verhagen E, Zwerver J, Gouttebarge V. Incidence, aetiology and prevention of musculoskeletal injuries in volleyball: a systematic review of the literature. Eur J Sport Sci. 2017;17(6):765-793; doi: 10.1080/ 17461391.2017.1306114.

13. Riemann BL, Schmitz RJ, Gale M, McCaw ST. Effect of ankle taping and bracing on vertical ground reaction forces during drop landings before and after treadmill jogging. J Orthop Sports Phys Ther. 2002;32(12):628635; doi: 10.2519/jospt.2002.32.12.628.

14. Lindenberg KM, Carcia CR. The influence of heel height on vertical ground reaction force during landing tasks in recreationally active and athletic collegiate females. Int J Sports Phys Ther. 2013;8(1):1-8.

15. Cesar GM, Pereira VS, Santiago PR, Benze BG, da Costa $\mathrm{PH}$, Amorim CF, et al. Variations in dynamic knee valgus and gluteus medius onset timing in non-athletic females related to hormonal changes during the menstrual cycle. Knee. 2011;18(4):224-230; doi: 10.1016/j. knee.2010.05.004.

16. Cesar GM, Pfeifer CM, Burnfield JM. 3-dimensional versus 2-dimensional comparison of knee valgus collapse during vertical jump: clinical implications for ACL risk of injury assessment. J Sports Med Ther. 2017;2: 32-38; doi: 10.29328/journal.jsmt.1001006.

17. Van Mechelen W, Hlobil H, Kemper HC. Incidence, severity, aetiology and prevention of sports injuries. A review of concepts. Sports Med. 1992;14(2):82-99; doi: 10.2165/00007256-199214020-00002.

18. Herrington L. Knee valgus angle during landing tasks in female volleyball and basketball players. J Strength Cond Res. 2011;25(1):262-266; doi: 10.1519/JSC.0b0 $13 \mathrm{e} 3181 \mathrm{~b} 62 \mathrm{c} 77$.

19. Vianna Spanó N, Pamplona Mariano F, de Andrade VL, de Souza Bedo BL, Palucci Vieira LH, Pereira Santiago PR. Neuromuscular training effect on knee rotation during drop landing in women [in Portuguese]. Rev Bras Med Esporte. 2016;22(2):92-96; doi: 10.1590/1517869220162202143722.

20. McGill R, Tukey JW, Larsen WA. Variations of box plots. Am Stat. 1978;32(1):12-16; doi: 10.2307/2683468.

21. Hopkins WG, Marshall SW, Batterham AM, Hanin J. Progressive statistics for studies in sports medicine and exercise science. Med Sci Sports Exerc. 2009;41(1):3-13; doi: 10.1249/MSS.0b013e31818cb278.

22. Hopkins WG, Batterham AM. The vindication of magnitude-based inference. Sportscience. 2018;22:19-29.

23. Leporace G, Praxedes J, Ribeiro Pereira G, Medeiros Pinto S, Chagas D, Metsavaht L, et al. Influence of a preventive training program on lower limb kinematics and vertical jump height of male volleyball athletes. Phys Ther Sport. 2013;14(1):35-43; doi: 10.1016/j. ptsp.2012.02.005.

24. Chappell JD, Creighton RA, Giuliani C, Yu B, Garrett WE. Kinematics and electromyography of landing preparation in vertical stop-jump: risks for noncontact anterior cruciate ligament injury. Am J Sports Med. 2007;35(2):235-241; doi: 10.1177/0363546506294077.

25. Alentorn-Geli E, Myer GD, Silvers HJ, Samitier G, Romero D, Lázaro-Haro C, et al. Prevention of non-contact anterior cruciate ligament injuries in soccer players. Part 1: Mechanisms of injury and underlying risk factors. Knee Surg Sports Traumatol Arthrosc. 2009;17(7): 705-729; doi: 10.1007/s00167-009-0813-1.

26. Yu B, Lin C-F, Garrett WE. Lower extremity biomechanics during the landing of a stop-jump task. Clin Biomech. 2006;21(3):297-305; doi: 10.1016/j.clinbiomech.2005.11.003.

27. Uchida TK, Delp SL. Biomechanics of movement. The Science of Sports, Robotics, and Rehabilitation. MIT Press; 2021.

28. Kristianslund E, Faul O, Bahr R, Myklebust G, Krosshaug T. Sidestep cutting technique and knee abduction loading: implications for ACL prevention exercises. Br J Sports Med. 2014;48(9):779-783; doi: 10.1136/ bjsports-2012-091370.

29. Krosshaug T, Nakamae A, Boden BP, Engebretsen L, Smith G, Slauterbeck JR, et al. Mechanisms of anterior cruciate ligament injury in basketball: video analysis of 39 cases. Am J Sports Med. 2007;35(3):359-367; doi: 10.1177/0363546506293899.

30. Kristianslund E, Krosshaug T. Comparison of drop jumps and sport-specific sidestep cutting: implications for anterior cruciate ligament injury risk screening. Am J Sports Med. 2013;41(3):684-688; doi: 10.1177/0363 546512472043.

31. Brown SR, Wang H, Dickin DC, Weiss KJ. The relationship between leg preference and knee mechanics during sidestepping in collegiate female footballers. Sports Biomech. 2014;13(4):351-361; doi: 10.1080/ 14763141.2014.955047.

32. Cowley HR, Ford KR, Myer GD, Kernozek TW, Hewett TE. Differences in neuromuscular strategies between landing and cutting tasks in female basketball and soccer athletes. J Athl Train. 2006;41(1):67-73.

33. Cortes N, Onate J, Abrantes J, Gagen L, Dowling E, Van Lunen B. Effects of gender and foot-landing techniques on lower extremity kinematics during drop-jump landings. J Appl Biomech. 2007;23(4):289-299; doi: 10.1123/jab.23.4.289. 


\section{HUMAN MOVEMENT}

B. Bedo et al., Knee kinematics of single-leg landing

34. Bressel E, Cronin J. The landing phase of a jump strategies to minimize injuries. J Phys Educ Recreat Dance. 2005;76(2):30-35; doi: 10.1080/07303084.2005.106 07332.

35. Moreno JH. Analysis of space and time parameters in indoor soccer. The distance travelled, the pace and direction of the player's movement during a competitive match [in Spanish]. Apunts Educ Fis Deportes. 2001;65:32-44.

36. Castagna C, Barbero Alvarez JC. Physiological demands of an intermittent futsal-oriented high-intensity test. J Strength Cond Res. 2010;24(9):2322-2329; doi: 10.1519/JSC.0b013e3181e347b9.

37. Buchheit M. A battle worth fighting: a comment on the vindication of magnitude-based inference. Sport Perform Sci Rep. 2018;31:v1. 